\title{
Todd Bridgman
}

\section{Empty Talk? University Voices on the Global}

Financial Crisis

The global financial crisis (GFC) which began in 2007 with a liquidity squeeze in the US banking system and which continues to play out today has affected us all, whether through the collapse of the finance company sector, rising unemployment, falling housing prices or the recession which followed the initial market crash. The speed and scope of the crisis surprised most experts - policy makers included. Specialists from a myriad of disciplines, from economics and finance to risk management, corporate governance and property, are trying to make sense of what happened, why it happened and what it means for us now and into the future. Members of the public rely on the news media to keep them informed of the crisis as it unfolds and they rely on experts to translate these complex events into a language which they can understand. The GFC is educating us all, and it is important that we all learn from it to avoid making the same mistakes again.
Todd Bridgman is a senior lecturer in the Victoria Management School at Victoria University of Wellington. This article is based on research conducted as part of a grant from the Marsden Fund.
In this article I report on my empirical study of public discussion of the GFC in New Zealand. I consider the contribution of New Zealand university academics alongside the contribution of others with expertise, and assess the performance of the mainstream news media in covering this global event of massive significance to our local communities. For me, the study raises questions for policy makers about how we view the role of universities in society and what the public can and should expect from their investment in them. Clearly, a number of academics have made valuable contributions to a public understanding of the impact of the GFC on New Zealand. The Institute of Policy Studies, for instance, hosted roundtable discussions on the GFC and the recession and in 2009 published contributions from five New Zealand economists in Policy Quarterly. Overall, however, I have concluded that, despite being a significant reservoir of knowledge in relation to many matters at the heart of the GFC, the public voice of our universities has been faint. Universities claim to be active public contributors and relevant to the communities which support them, but, at least in the case of the GFC and its effects on New Zealand, these claims sound like empty talk. I want to stress that this is not all of their own making, however, since in many ways their actions can be seen as rational responses to the policy environment they inhabit, which 
places little value on communication with a lay audience. Another contributing factor is an increasingly resource-starved and commercialised mainstream news media, which makes the inclusion of academic voices less likely.

Veteran broadcaster Paul Holmes recently lamented the quality of expert comment on the New Zealand economy, describing economists who appear in the media as 'fundamentally, intellectually dishonest' (Holmes, 2010). According to Holmes, those who work for banks cannot be trusted because their employers have a commercial incentive to maintain confidence in the economy. Those working for economic research firms are also suspect because they depend on corporate clients for their survival. If we can't listen to them, who can keep us informed about New Zealand's economy? Interestingly, Holmes makes no mention of academics. 'The only people who know what is really going on, fundamentally, are the shopkeepers and Fonterra.' I mention Paul Holmes because his comments highlight a central theme to emerge from my research: that academics are largely forgotten when we consider sources of expert comment on major events such as the GFC. When we hear an economist talking in public about the economy, chances are it will not be a university economist, but rather an economist employed by a large bank or a research consultancy. This applies not just to economics, but to other disciplines relevant to the GFC, such as finance, property, law and management. My study explored why this is the case, what the implications are for the quality of public discussion and what could be done if we wanted academics to play a more active public role. In the following section, I provide an overview of the study, followed by some key findings. I then consider what is distinctive about the voice of academics, and conclude by suggesting how we might strengthen that voice to take more seriously our responsibility as public educators.

\section{Universities as the 'critic and conscience' of} society

The impetus for the research was a suggestion that globally, the universitybased 'public intellectual', defined as an academic who has a commitment to speaking in the public domain, is in a state of decline and that this adversely effects the quality of public debate (Jacoby, 1987; Posner, 2001). 'Public intellectual' is not a term that rests easy with New Zealanders. Turner (2007, p.85) concludes that 'just talking about public intellectuals makes you ... a wanker rather than a wellrounded bloke'. New Zealand's small population, geographical isolation, a
What does it mean for universities to act as the critic and conscience of society? Wilf Malcolm, a former chair of the New Zealand Vice-Chancellors' Committee who pushed for its adoption, describes it as an enabling function which provides people with the knowledge and understanding to be able to exercise judgement. Performance of the critic and conscience role takes place in the

\section{The contribution of New Zealand academics to our public conversation on the GFC has been muted, in comparison with other experts, apart from a small number who have made frequent comments.}

prevalence of colonial attitudes and a pioneer culture which privileges Kiwi ingenuity over academic achievement is said to create an environment which is hostile to intellectualism, especially in the public arena (Horrocks, 2007).

The public role of academics is an issue particularly relevant for New Zealand because our universities are distinctive for having a statutory obligation to act as the 'critic and conscience' of society (Education Act, 1989). The philosophical origins of this obligation can be traced to Cardinal John Henry Newman's 1852 lectures on The Idea of a University. For Newman, the purpose of a university education was to cultivate the intellect, both within the boundaries of the university and beyond, in order to better enable people to make sense of their world (Newman, 1976). The term 'critic and conscience' emerged out of the 1988 Hawke report on tertiary education (Hawke, 1988) and subsequently found its way into the Education Act. The act identifies five characteristics that distinguish universities from other tertiary institutions: universities are primarily concerned with advanced learning; research and teaching are closely connected; universities are international in their standing; they are a repository of knowledge; and they accept a role as critic and conscience of society (Education Act, 1989). classroom, through research and also through engagement with the wider life of a community (Malcolm and Tarling, 2007). It is made possible through the protection of academics' freedom to 'question and test received wisdom, to put forward new ideas and to state controversial or unpopular opinions' (Education Act, 1989).

My own institution, Victoria University, has recognised these obligations as 'public contribution', one of eight strategic goals in its 2009-2014 plan (Victoria University, 2008a). According to the former chancellor, Emeritus Professor Tim Beaglehole:

We want to ensure our research and knowledge are shared with the public in a way that enriches New Zealand's culture, society and economy. Victoria University's staff and students are well placed to contribute to the opportunities and challenges in the world today and we will continue to encourage and support staff in their role as the critic and conscience of society. (Victoria University, 2008b)

For the purposes of the study, 'public contribution' was defined broadly and included public presentations, appearances in the media, material written for a general audience, blogs, submissions to public bodies and 
various engagements with community organisations. My assessment of the contribution of academics was based on an extensive archival search of online news databases, university websites and other online content such as blogs, as well as 43 interviews conducted with academics, other experts and members of the media. The study does not provide an objective measure of academics' public contribution vis-à-vis other experts. However, the qualitative data provides convincing evidence that New Zealand academic voices on the GFC have been muted. the GFC has been muted, in comparison with other experts, apart from a small number who have made frequent comments. This group of active academic contributors are typically driven by the desire to have an impact on policy, practice and the wider community, with many seeing their public work as a service to the public, in return for the public funding of universities. Most felt that, while such work benefited their university by providing it with good publicity, the university did little to recognise or reward their efforts. In contrast, the group of expert commentators who were not

\section{Respondents from the media typically found it difficult to find academics willing to comment publicly and felt academics needed to become better at speaking in a language accessible to those without specialist expertise.}

Through my analysis of the archival data I identified academics who had regularly commented on various aspects of the GFC, including economics, finance, corporate governance, property, tourism, agriculture and politics, as well as academics in these fields who have not been active in public, to understand why. All of New Zealand's eight universities were represented in the sample. I also talked to experts who made public comments but are not academics, such as bank economists, private sector economists and spokespeople for various interest groups, such as unions and employer associations, to learn more about their motivations for undertaking such activity, as well as their perception of the contribution of academics. Finally, I spoke with people in the media, including journalists, journalism educators and media commentators to discuss their interactions with academics and other expert sources.

\section{The faint voice of academics}

The contribution of New Zealand academics to our public conversation on academics had stronger institutional support for their efforts. Economists and other private sector experts spoke of the commercial benefits of their public commentary in building their organisation's profile and credibility, while interest group spokespeople saw their public engagements as an effective way of ensuring their organisation's perspective was heard.

Many of the academics interviewed, including both those active in providing public commentary and those who are not, regarded regular engagement with the wider public, particularly through the media, as detrimental to an academic career. This work is time-consuming, which leaves less time for 'outputs' which are accorded higher value, especially research articles in academic journals. Respondents spoke at length about the negative influence of the PerformanceBased Research Fund (PBRF), which began with an initial round in 2003 and is nowadays an increasingly important funding stream for universities based on their research performance. Some felt the PBRF discouraged them from undertaking research on the New Zealand context, because it placed greatest value on research published in prestigious international journals, many of them in the US, which were not much interested in New Zealand. As a result, research that was relevant to local communities and which could have genuine impact on those communities was forgone in the pursuit of research more likely to appeal to an international audience. A combined effect was home-grown researchers losing touch with New Zealand issues and university departments increasingly seeking to recruit international faculty with excellent publication records but little interest in local concerns, such as New Zealand's experience of the GFC. Not everyone blames the PBRF for the retreat of academics from the public sphere. One respondent believed that it predates the PBRF, beginning in earnest with the election of the fourth Labour government in 1984, when academics became genuinely fearful of putting their heads above the parapet.

A lack of incentive is not the only reason for academics to shy away from public commentary. Those who speak in public can attract strong criticism and sometimes the threat of legal action. Many academics avoid media requests because of a fear of their views being misrepresented by journalists, although those academics active in the media accept this as an unfortunate but inevitable consequence of not being in control of the way stories are presented. Some academics avoid public interactions because they want to avoid trivialising academic knowledge, or, perhaps more importantly, want to avoid being seen by their academic colleagues as engaging in that process. Others questioned whether they were sufficiently in touch with current events to offer anything meaningful to the conversation.

Respondents from the media typically found it difficult to find academics willing to comment publicly and felt academics needed to become better at speaking in a language accessible to those without specialist expertise. Experts outside the university have dominated the public discussion of the effects of the GFC on New Zealand partly because they are adept at providing what the media 
are looking for. Bank economists, for instance, understand well the news media's predisposition towards sources that are suitable, available and accessible. Bank economists can talk on a wide range of issues, from interest rates to immigration, business confidence to housing, exchange rates and commodity prices. They watch closely the daily flow of economic data and are therefore well positioned to offer expert comment at short notice and they are also highly skilled in speaking in a language the public can understand.

But does it matter if academics have contributed little to the public's understanding of the GFC and its effects on New Zealand? What, if anything, are we missing out on? There was a consensus amongst respondents that academics are perceived as more independent than other sources of expertise. They believed that when academics speak, they do so as individuals, whereas almost all others who contribute in public are spokespeople for organisations, which are perceived as having vested interests in promoting particular viewpoints. Paul Holmes' distrust of bank economists is a case in point. The bank economists I spoke to vigorously refute this suggestion, pointing out that their influence depends on their credibility, which would be nil if their expert comments bore little relation to economic reality. Rather than deliberately misleading the public and 'talking their book', as Holmes claims, several respondents felt that bank economists were likely to avoid discussing issues which placed the actions of the banking sector in a negative light. It was important, therefore, to have other experts in economics and finance, especially academics, to provide an independent view. For their part, bank economists were supportive of greater involvement by academics, acknowledging that academics were better equipped to provide the 'big picture' overview of the economy, as well as to put today's economic events in a broader historical context.

Having said that, it would be naïve to assume that the independence of universities is absolute. None of the journalists interviewed routinely ask academics if they have conflicts of interest, yet many academics have private research and consulting arrangements which could raise conflicts on various issues. In addition, New Zealand universities routinely seek funding from industry, such as the University of Canterbury's agreement in 2005 with Provincial Finance to fund a professorial chair in investment finance (University of Canterbury Foundation, 2005). The university hoped the deal would strengthen ties with the business community, fund world-class research and contribute to the economic development of the region, but Provincial Finance was put into receivership the following year. In light of the collapse of the finance company sector, we should be mindful about the potential influence which corporate funding has on the government seems mindful of criticism that the PBRF discourages academics from engaging with audiences outside the university, recognising that 'research in universities needs to combine excellence with impact' (ibid., p.16). But impact is defined narrowly: 'We will ensure that the Performance-Based Research Fund recognises research of direct relevance to the needs of firms and its dissemination to them' (ibid.). When policy makers regard universities as the handmaiden of industry we should not be surprised when they pay lip service to their critic and conscience obligations.

We also need to be mindful of the ability of our news media to transmit the voices of academics. New Zealand's

\section{We also need to be mindful of the ability of our news media to transmit the voices of academics. New Zealand's population means we have a small media with little diversity amongst the mainstream print and broadcast offerings and limited funding for public broadcasting.}

capacity of universities to act as the critic and conscience of society. If we want our academics to be a source of independent expert comment on the state of an industry, do we want them reliant on that industry for funding?

\section{Strengthening the voice of academics}

In defence of universities, they have simply mirrored policy makers' neglect of the critic and conscience role. It is clear from government's Tertiary Education Strategy 2010-15 that the priorities for the tertiary sector lie elsewhere. The government's vision is for tertiary education to act as a driver of productivity and economic growth - 'tertiary institutions need to work more closely with business to ensure that research meets the needs of the economy' (Ministry of Education, p.7) - in essence what the University of Canterbury set out to achieve through its relationship with Provincial Finance. The population means we have a small media with little diversity amongst the mainstream print and broadcast offerings and limited funding for public broadcasting. As a former journalist, it was sad to encounter through this research a widespread feeling of despondency about the current state and future prospects of journalism in New Zealand. Mass media organisations, especially newspapers, have been hit hard by the GFC, at a time when they were already struggling to deal with the implications of technological advances on their business model. Newsrooms have always struggled to retain their experienced personnel because of the lure of higher paying jobs in public relations, but, with them now having to operate on small budgets, there are even fewer senior reporters with the knowledge and experience to pursue complex stories of major public interest, such as the GFC. One journalist identified a trend towards 
'churnalism', where press releases are published with little or no intervention by a journalist, either to check facts or source an opposing view. The quality of New Zealand's business and economic journalism is especially vulnerable as there is no specialised training and it is not a popular destination for graduates. This environment of increasingly scarce resources reinforces journalists' reliance on their established sources, such as bank economists, on whom they can rely to provide an informed comment at short notice, and makes it less likely that they will search out an academic perspective, unless they are already an established source.

The end result is a New Zealand mass media ill-equipped to perform their function as the 'fourth estate' by holding
Zealand universities' neglect of their statutory responsibility to act as the critic and conscience of society. Apart from being an effective means to raise their profile and demonstrating that the university is engaged with contemporary issues, there are few tangible rewards for universities making an active public contribution. There are some costs, since it reduces the time academics have for the seemingly all-important task of performing on the PBRF. In a more conducive policy environment, there is much more universities could do to encourage, support and recognise the public contributions of academics, including giving this work greater weight in promotion processes, creating awards to recognise outstanding public contributions, awarding honorary degrees

\section{The risk for universities is that they have limited control over the public contributions of their faculty, since they speak as individuals and not on behalf of the university.}

powerful institutions in our democracy accountable for their actions. In an increasingly commercialised industry, it is becoming less obvious that they even identify with those responsibilities. Capital + Merchant Finance sponsored TVNZ's nightly news updates until it was placed in receivership in 2007, and we must not forget TVNZ's infamous voiceover provided by former news presenter Richard Long: 'This One Weather Update is brought to you by Hanover, a New Zealand business with the size and strength to withstand any conditions.' Might New Zealanders have been better informed by our public broadcaster about the finance company sector without commercial arrangements such as this?

The extent of academics' public contribution depends on a range of interactions between the funders of universities, universities, the media, and of course, individual academics. There are, then, no simple solutions to New to those in society who act as critic and conscience, making media training for academics more freely available and getting those academics active in public to mentor colleagues.

An issue for policy makers is whether the PBRF, in its current form, really provides taxpayers with value for money from their investment in university research. When New Zealand's academics have such little to say in public about an issue as significant as the GFC, perhaps this is indicative of good intentions producing unintended consequences. The PBRF could be changed to value more highly research published locally, and greater weight could be given for academics having an impact on a wider audience than other academics and even industry; but then measuring impact is problematic.

It should also be remembered that there is risk for universities in encouraging their academics to reach out to the public. Acting as critic and conscience might involve raising difficult questions, exposing uncomfortable facts and presenting unpopular positions, meaning the potential for controversy is ever-present. A recent example of this concerned the comments of Massey University management academic Greg Clydesdale, who, in 2008, sent a report to New Zealand media which questioned the economic contribution of Pacific Islanders' to New Zealand society. The report became the lead story in Wellington's Dominion Post newspaper, sparking accusations of racism and counter-claims of political correctness, which led to a review by the race relations conciliator. Two peer reviews commissioned by the Ministry of Pacific Island Affairs questioned the quality of Dr Clydesdale's research, and, while Massey University had concerns about the way he had made the work public, it affirmed his right to academic freedom (Chalmers and Ling, 2008).

Without entering into the debate about the quality of Dr Clydesdale's work, the manner in which he distributed it to media or the actions of the Dominion Post in giving it such prominence, Dr Clydesdale was asserting his role, and that of Massey University, as the critic and conscience of society. The risk for universities is that they have limited control over the public contributions of their faculty, since they speak as individuals and not on behalf of the university. While universities have staff whose job it is to manage public communications, academics will often work independently of them. We must be careful that the freedom of academics be respected because if academics can only make public comments which are approved by their universities, the very essence of the critic and conscience role will have been lost.

This article has focused academics' engagement with a wider public, but I acknowledge that this is but one form of public contribution. Many academics are active in providing expertise to various public bodies and in conducting research for government. For example, my own dean, Professor Bob Buckle, had a recent high-profile appointment as chair of the Tax Working Group, an independent group of experts endorsed by government 
ministers to consider tax policy challenges facing New Zealand. I am also aware that academics from a range of policy fields have been advising the government behind the scenes on their response to the GFC. My aim is not to discount these activities, but to suggest that there is also a responsibility for academics to engage with an audience beyond academics, policy makers and others with specialist expertise. This is the concept of academics as public educators, helping to translate complex events in a manner accessible to a lay audience.

While it has become common for governments around the world, including New Zealand's, to justify public expenditure on tertiary education with reference to productivity and economic growth, we would be foolish to neglect the broader contributions of universities to society. The events of the GFC have challenged received wisdom about risk, the financial services industry, corporate governance and many other aspects of business. Experts who work New Zealand universities have been largely silent in public about these issues. Our understanding of the effects of the GFC on New Zealand, and therefore our ability to avoid making the same mistakes again, is poorer for that. One hopes that we can learn from this experience to take more seriously universities' fulfilment of their distinctive role as the critic and conscience of society.

\section{References}

Chalmers, A. and J. Ling (2008) 'Massey faces claims of supporting poor research', Dominion Post, 7 June

Hawke, G. (1988) Report on Postcompulsory Education and Training in New Zealand, Wellington: [Office of the Associate Minister of Education]

Holmes, P. (2010) 'We had it all, then we spent it all', New Zealand Herald, 15 August

Horrocks, R. (2007) 'A short history of "the New Zealand intellectual"', in L. Simmons (ed.), Speaking Truth to Power, Auckland: Auckland University Press

Jacoby, R. (1987) The Last Intellectuals: American culture in the age of academe, New York: Basic Books

Malcolm, W. and N. Tarling (2007) Crisis of Identity? The mission and management of universities in New Zealand, Wellington: Dunmore Publishing
Ministry of Education (2010) Tertiary Education Strategy 2010-15, Wellington: Ministry of Education

Newman, J.H. (1976) The Idea of a University, Oxford: Clarendon Press

Posner, R. (2001) Public intellectuals: a study of decline, Cambridge, MA: Harvard University Press

Turner, S. (2007) 'The public intellectual is a dog', in L. Simmons (ed.), Speaking Truth to Power, Auckland: Auckland University Press

University of Canterbury Foundation (2005) 'Provincial Finance directors investing in their past', University of Canterbury Foundation Newsletter, 4, July, pp.1-2

Victoria University of Wellington (2008a) Strategic Plan 2009-1014, Wellington: Victoria University of Wellington

Victoria University of Wellington (2008b) Annual Report 2008, Wellington, Victoria University of Wellington
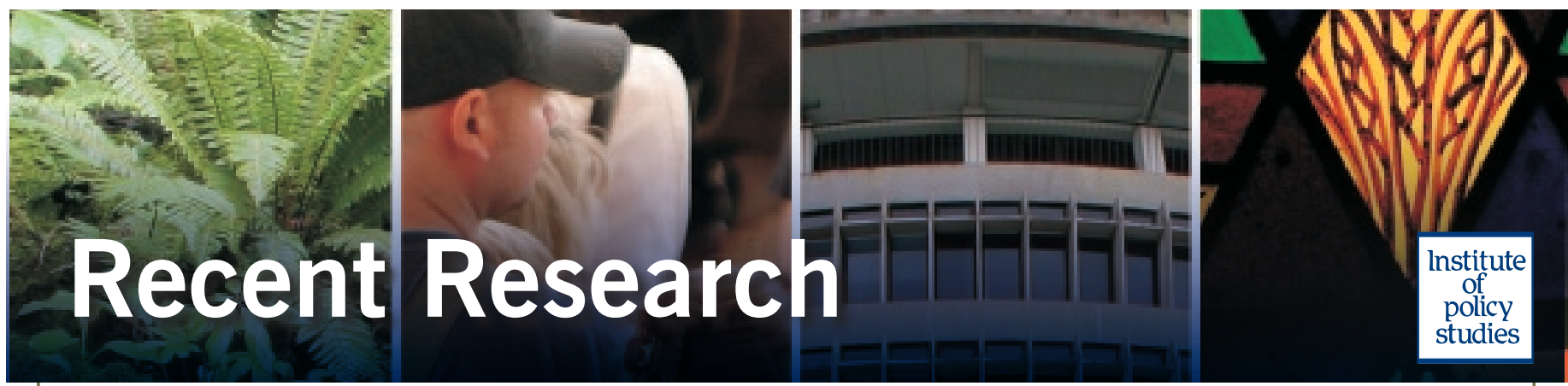

A loss of 'white' male privilege? Gender and ethnic dimensions of domestic student participation in bachelor degree studies

by Paul Callister

Against a background of constrained government finances that have led to the government capping funding for bachelor degree study, this research considers the changing ethnic and gender composition of domestic students. In particular, it explores who is now under-represented in bachelor level study.
Why are a group of mid-life men on the margins of work and family? A literature review

by Paul Callister and David Rea

Since the 1960s and 1970s New Zealand and other industrialised countries have moved away from a situation where most mid-life men were in full-time paid work, married and living with dependent children, highly unlikely to be in receipt of benefit income, and most likely to be economically supporting their partner and children. This study explores why these changes have taken place.

IPS WP 10/13 October 2010 